\title{
E-Procurement Adoption at the Municipal Level: Influence of Organizational, Technological and Environmental Factors
}

\author{
Daniel J. Veit, Nils P. Parasie, Jan C. Huntgeburth \\ Dieter Schwarz Chair of Business Administration, E-Business and E-Government \\ University of Mannheim, Business School \\ Schloss, 68131 Mannheim, Germany \\ \{veit, parasie, huntgeburth\}@bwl.uni-mannheim.de
}

\begin{abstract}
In spite of high potentials and sophisticated goals set by federal governments, municipalities are reluctant to move procurement to the Internet. This study focuses on determinants of E-Procurement adoption at the municipal level. Considering previous research as well as public and private sector differences, a research model is developed, which is further examined by collecting and analyzing data from a multiple-case study of 13 German municipalities. Based on the empirical results, practical implications and areas of future work are discussed.
\end{abstract}

\section{Introduction}

E-Government is defined as the public sector's use of Information and Communication Technology (ICT) and aims at improving the efficiency, effectiveness, transparency and responsibility of governments [38]. E-Government has been attracting increasing research interest over the last years and is a domain with growing reputation.

An important subset of E-Government is E-Procurement, which refers to the use of the Internet in conducting public procurement to purchase public supplies, services and works. While several researchers have already investigated the barriers and determinants of E-Procurement adoption at the federal and state level [e.g. 27], municipalities have only rarely been the units of analysis. Against the background of highly decentralized public procurement markets in Europe where municipalities typically award a lion's share of public contracts [12], this paper pays attention to E-Procurement adoption behaviors at the municipal level.

The use of E-Procurement in the public sector raises high expectations. Governments are the largest buyers in the EU accounting for $16 \%$ of the European Gross Domestic Product [12]. From the public administration's point of view, moving procurement to the Internet essentially saves process costs through time and resource savings as well as product costs through intensified competition on public contracts [8]. Moreover, the tools commonly used to carry out E-Procurement help to improve the quality and transparency of procurement procedures and to relieve procurement units dealing with complex and highly regulated processes.

In spite of these potentials and ambitious goals set by federal governments [26], municipalities are reluctant to move their procurement activities to the Internet. A recent survey of 63 large cities in Europe highlights that sophisticated procurement services are the exception rather than the rule [20]. While tender notices are increasingly published in online databases, the targeted capability to complete entire procurement processes online is far from being implemented. Therefore, the goal of this paper is to get a better understanding of the motives and determining factors of E-Procurement adoption at the municipal level.

The process of understanding begins with the concepts, terms, and jargon of the phenomenon under investigation. Therefore, the context of E-Procurement at the German municipal level is presented in the following section. Section three, presents the reviewed literature and as a result a conceptual model on E-Procurement adoption. The research model is the starting point for the qualitative analysis. In the first part of section four, the case study research design of the multiple-case study of 13 German municipalities is presented. In the second part, the results of the analysis are reported and discussed. The last section sums up and discusses future research topics.

\section{E-Procurement}

In contrast to the private sector, public procurement requires a bureaucratic procedure to be followed as it is regulated by regional, national and international agreements. In Germany, public procurement awarding procedures are predominantly determined by the three 
Contracting Rules for the Award of Public Contracts $\left(\mathrm{VOL} / \mathrm{A}^{1} / \mathrm{VOB} / \mathrm{A}^{2}, \mathrm{VOF}^{3}\right)$.

The Contracting Rules explicitly allow the use of electronic means throughout the whole public procurement process $(\S 16(4) \mathrm{VOL} / \mathrm{A}, \S 16(3)$ No. 1 $\mathrm{VOB} / \mathrm{A}, \S 4(6) \mathrm{VOF})$. Moreover, decisive criteria for tools to be used for electronic communication are set: the tools must be non-discriminatory, generally available and interoperable with the ICT products in general use $(\S 16(5) \mathrm{VOL} / \mathrm{A}, \S 16(3) \mathrm{VOB} / \mathrm{A}, \S 4(7)$ VOF). As such, the Internet is permitted as a medium of transferring electronic bids, request to participate or other documents in the context of awarding public contracts.

A full and legally compliant E-Procurement process between economic providers and contracting authorities requires a considerable number of functionalities available to a municipality. A municipality needs to be capable to publish public notices, to provide access to contracting documents, to process bids, signatures and evidences, to conclude contracts with the winning bidder, to send orders, to receive invoices and to finally settle the contract over the internet [8].

In the public sector, two types of E-Procurement tools are commonly used that cover the basic functionalities: Namely tendering platforms and catalogue systems. Software solutions, which can be assigned to one of the two types may vary on the degree they implement the functionalities and on the level of integration in existing ICT systems [28].

A tendering platform covers formal procurement procedures like the open or restricted procedure. The platform allows a contracting authority to publish public notices, to supply the contract documents to candidates and to receive bids [8]. High-value purchases like constructing works or consulting services are typically procured through tendering platforms. The submission of bids requires the processing of electronic signatures, attestations and catalogues. Tendering platforms can be integrated into existing ICT systems, e.g. tools that compile contracting documents or assess bids. Even more advanced solutions may also cover the implementation of the contract, which involves contracting, invoicing and payment [36].

\footnotetext{
${ }^{1}$ Contracting Rules for the Award of Contracts for Public Supplies and Services ("Verdingungsordnung für Leistungen, Teil A") on 29th December 2009, Federal Gazette ("Bundesanzeiger") No. 196a

${ }^{2}$ Contracting Rules for the Award of Contracts for Construction Services ("Vergabe und Vertragsordnung für Bauleistungen, Teil A") on 20th March 2006, Federal Gazette No. 94a

${ }^{3}$ Contracting Rules for the Award of Contracts for Professional Services ("Verdingungsordnung für freiberufliche Leistungen") on 18th November 2009, Federal Gazette No. 185a
}

In contrast, a catalogue system deals with informal procurement procedures like direct purchases or orders based on framework agreements [35]. Catalogue systems allow requesters of goods and services to search for and select products in electronic catalogues, which are authorized and negotiated by central procurement in advance [30]. Standardized products like stationery or books are typically purchased through catalogue systems. More advanced systems cover the processing of invoices and payment as well as the integration into existing ICT systems, e.g. enterprise resource planning or financial accounting.

Having introduced the key concepts, terms, and jargon of E-Procurement at the municipal level, the next section provides the theoretical foundation for our study of E-Procurement adoption among German municipalities.

\section{Theoretical foundation}

\subsection{Literature review}

A variety of research streams, which are related to E-Procurement adoption at the municipal level, can be identified in the literature.

Comprehensive research is conducted on technology adoption by organizations and individuals. Most of the underlying theories are adopted from psychology [e.g. Theory of Reasoned Action, 13] or sociology [e.g. Innovation Diffusion Theory, 34] and tailored to information systems context. The most prominent theories are the Technology Acceptance Model (TAM) of Davis [11] and the Innovation Diffusion Theory (IDT) of Rogers [34]. Both TAM and IDT utilize attributes of an innovation to predict IT acceptance and are successfully applied in studies on technology adoption. However, the literature suggests that using universal factors like perceived usefulness may be inappropriate, when the innovation context and the units of analysis become more complex and specific [6].

Swanson [37] expects systematic differences in adoption and evolution patterns among types of innovation. Just like E-Procurement, Electronic Data Interchange (EDI) aims at integrating suppliers and customers in an Inter-Organizational System (IOS) [18]. The research on EDI adoption was mainly motivated by the fact that small organizations are particularly reluctant to implement EDI. Existing studies reveal that small organizations are more concerned with the activities of their trading partners than with the characteristics of the technology as such [2]. Reviewing prior works on EDI adoption, Chwelos et al. [9] find that three factors influence 
adoption: Namely readiness, perceived benefits and external pressure. They argue that while the benefits of EDI or external pressure may motivate the adoption of EDI, engaged organizations must have organizational capabilities and willing trading partners before EDI is adopted.

While most of EDI research was conducted in the 1990 s, researchers have increasingly paid attention to open standard IOSs within the last ten years. As opposed to EDI, open-standard IOSs use the Internet as the delivery platform and typically rely on open exchange formats like XML or UBL. According to Zhu et al. [45], firms' migration to open-standard IOSs is mainly influenced by network effects and switching costs.

In relation to E-Procurement, E-Commerce is a broader domain of study comprising not only the buying but also the selling, transferring and exchanging of products, services or information via the Internet [40]. Grandon and Pearson [16] show that apart from top-managers' strategic value perceptions, E-Commerce adoption among small and medium enterprises is determined by perceived usefulness and perceived ease of use (both adapted from TAM), external pressure and organizational readiness (both adopted from EDI research) as well as compatibility.

The literature on technology adoption is mainly developed for and applied to the private sector. However, public and private organizations are different in many aspects [31]. Considering these differences, many adoption factors need to be redefined when the unit of analysis is a public organization [22].

Several works can be identified that offer explicit theories or models of E-Government evolution and development. However, a common critic is that these models assume that governments will increasingly adopt more and better E-Government [10]. While the adoption of information services is progressing rapidly, the movement toward integrated and transactional E-Government is progressing much more slowly, if at all. The growing literature on E-Government adoption is reviewed by Titah and Barki [38]. Apart from IT design characteristics, adoption is influenced by managerial practices as well as organizational and individual characteristics. Although factors like trust, usefulness and ease of use are mainly applied in the context of online citizen services [4], they are likely to apply also to the context of E-Procurement at the municipal level.

The adoption of E-Procurement in the public sector is studied by researchers from two different perspectives. One major stream of research focuses on success factors of regional or national E-Procurement initiatives.
The debate about the level of centralization of computing infrastructure is important to many areas of E-Government. Caudle et al. [5] argue that differences among private and public organizations are reflected in several information system issues that are unique to information systems in the public sector. While private organizations often treat information systems as proprietary and use them as a competitive advantage, the public sector can use technology transfer strategies to increase sharing of applications and technical assistance among public organizations. However, such a strategy assumes that all involved actors are rational and share the same ideas in improving the overall performance of the public sector [32].

There is controversial debate about the degree of centralization of decision making, i.e. who decides on demand and suppliers. Gurbaxani and Whang [17] analyze this trade-off from an economic perspective. They argue that in the optimal organizational structure the internal coordination costs are at a minimum. As E-Procurement reduces decision information costs more than the agency costs, public procurement should be further centralized within the public sector [32].

Henriksen and Mahnke [19] analyze low take up rates of a centralized procurement system in Denmark. They argue that although the economic rationalities behind adoption of the system are widely shared across the public sector, this is not enough for adoption. The authors conclude that centralized E-Procurement solutions contradict with decentralized procurement power and propose that the political structural context needs to be considered as much as the potential benefit to better explain E-Procurement adoption.

Apart from centralization versus decentralization issues, Vaidya et al. [41] propose several success factors for the implementation of E-Procurement initiatives. Based on a literature review, they identify involvement of end-users and suppliers, process reengineering, and system integration as the most important success factors.

Another stream of research focuses on contextual factors of public institutions that influence the adoption of E-Procurement. Based on secondary data, Reddick [33] analyzes the extent of E-Procurement adoption in American state governments. He shows that a high management capacity and a low tax capacity are positively related to E-Procurement adoption. Reddick argues that fiscally stressed and managerial innovative state governments see E-Procurement as a new mechanism to reduce costs and save resources and hence, are more active in adopting various E-Procurement tools.

A similar study on American state governments is conducted by Moon [27]. Moon shows that state government size, procurement professionalism, 
empowerment of the central procurement unit and managerial innovation orientation are important determinants of E-Procurement adoption among state governments. He argues that a larger state government is more likely to adopt because it has more resources to pursue E-Procurement adoption. Moreover, state governments with centralized and professional procurement units are more sensitive to new ideas, tend to value managerial characteristics like efficiency and effectiveness and are thus more active in adopting E-Procurement.

\subsection{E-Procurement adoption model}

The lack of studies on E-Procurement adoption at the municipal level precludes the option of directly building on existing theories. A review of the literature suggests that the Technology-OrganizationEnvironment Framework as proposed by Tornatzky and Fleischer [39] may provide a useful starting point to explore E-Procurement adoption [7]. According to the framework, a technological innovation decision is mainly driven by the organizational, technological and environmental context of the organization. The framework is already successfully used in and adapted to other information systems contexts.

Recalling previous research and the differences of private and public organizations, the model is adapted to the specific context of public procurement (see Figure 1).

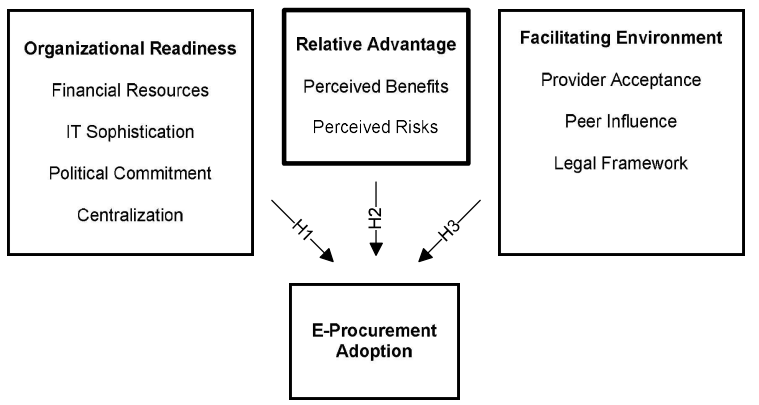

Figure 1. E-Procurement adoption model

3.2.1. Organizational readiness. The organizational context is labeled Organizational Readiness to reflect that organizational factors lay the foundation for the successful adoption of E-Procurement among municipalities [21].

The impact of E-Procurement is influenced by the level of integration in existing IT systems. However, integration is costly due to organizational reorganization and costs for hardware and software. In the context of EDI adoption, Chwelos et al. [9] show that while benefits and external pressure motivate adoption, motivated organizations must have capabilities like Financial Resources or IT Sophistication before the technology can be adopted. Resulting, the following hypotheses are put forth:

Hypothesis 1a: The financial resources available are positively associated with the degree of E-Procurement adoption.

Hypothesis 1b: The degree of IT know-how and competences is positively associated with the degree of E-Procurement adoption.

Previous research reveals that further organizational characteristics need to be considered studying adoption of E-Procurement at the municipal level [27, 33]. Apart from available resources, public managers need sufficient resources and mandate of the political leadership to successfully adopt E-Procurement. As argued by Henriksen and Mahnke [19], the political structural context needs to be considered as much as the economic rationalities to better explain E-Procurement adoption. Politicians whose primary objective is to support local providers are unlikely to support public managers improving transparency and competition through E-Procurement. In contrast, when local politicians give fairness and cost-effectiveness goals priority over concerns for local providers, it is more likely that E-Procurement capabilities are further developed.

Hypothesis 1c: The degree of politicians' commitment to modernize public procurement is positively associated with the degree of E-Procurement adoption.

Moon [27] shows that the empowerment of the central procurement unit is another important determinant of E-Procurement adoption. The empowered employees decide on the public supplies, services and works that the organization requires and from which supplier it is procured from. He argues that it is much easier to take an adoption decision when a strong leadership of the central procurement unit is involved. As a result, the following hypothesis is put forth:

Hypothesis 1d: The degree of procurement centralization is positively associated with the degree of E-Procurement adoption.

3.2.2. Relative advantage. While previous research on E-Procurement mainly focuses on organizational factors, technological factors are rather unattended. The technological context is labeled Relative Advantage to reflect that decision-makers mainly assess the risks and benefits of E-Procurement adoption when a decision needs to be made.

The Relative Advantage is the degree to which E-Procurement is perceived as being better than paperbased procurement. According to Rogers [34], the 
Relative Advantage is one of the strongest predictors of an innovation's rate of adoption in a social system. Therefore, the following hypotheses are put forth:

Hypothesis 2a: The perceived benefits of adopting E-Procurement are positively associated with the degree of E-Procurement adoption.

Hypothesis 2b: The perceived risks of adopting E-Procurement are negatively associated with the degree of E-Procurement adoption.

3.2.3. Facilitating environment. The external environmental context is labeled Facilitating Environment to reflect the supporting characteristic of external factors on E-Procurement adoption. The Facilitating Environment refers to the conditions that are largely out of the municipality's control but positively influence a municipality's adoption decision.

The lack of IT equipment and competences in particular among small enterprises is a key barrier of E-Government proliferation [24]. From an economic perspective, the power in particular of small enterprises over municipalities converges to zero as administrations can easily substitute providers [18]. However, the political structural context may affect public manager's concerns when the support of local providers is an important politico-economic goal that is given priority [23]. As a result, the following hypothesis is put forth:

Hypothesis 3a: The degree of E-Procurement acceptance among local providers is positively associated with the degree of E-Procurement adoption.

According to Rogers (2003), the exchange of experiences among peer organizations like neighboring municipalities or the state government reduces uncertainty and is fundamental for the diffusion process [34]. Adopting peers may encourage or even pressurize municipalities to adopt as well because the more public organizations join a shared initiative the more it attracts other public organizations and providers to join. As a result, the following hypothesis is put forth:

Hypothesis 3b: The degree to which peer organizations provide experiences about E-Procurement is positively associated with the degree of E-Procurement adoption.

As discussed in section two, the way public procurement is carried out at the municipal level is influenced by the legal framework set by international, national and state authorities. A legal framework that clearly fosters the use of electronic means throughout the whole public procurement process positively influences the adoption of E-Procurement. Conclusively, the following hypothesis is put forth:

Hypothesis 3c: The degree to which the legal framework fosters the use of E-Procurement is positively associated with the degree of E-Procurement adoption.

\section{Qualitative analysis}

The qualitative analysis follows the multiple-case study method as proposed by Yin [44] to further elaborate the conceptual model. On the one hand, corroboration of the proposed influence factors is sought. On the other hand, the investigation aims at identifying additional influence factors by incorporating practitioners' feedback. Throughout the research process, rigorous strategies are used to improve the overall quality of the research design and thus the credibility of the results.

\subsection{Case study design}

As opposed to survey research, case study research aims at generalizing results using analytical rather than statistical generalization [44]. If all examined cases provide compelling support for the set of propositions, the theory is likely to be transferable to comparable cases with similar determining factors.

The number and selection of cases is central to the design of a case study [1]. Studies grounded on one versus studies based on a large number of cases typically pursue different research goals and are driven by different shapes of the empirical universe under investigation.

The purpose of a single-case study usually is to understand the internal mechanisms of the case and to generate a theory on the phenomenon under investigation [14]. For this reason, single case studies are most commonly used in the initial phase of knowledge accrual [1]. Opposed to that, a study with a large number of cases is often applied in the later stage of knowledge accrual and somewhat restricted testing in- and output effects [14].

Besides research goals, design decisions are also driven by the shape of the population under investigation. Yin [44] argues that the rationale for conducting a single-case as opposed to a multiple-case study is when the case represents a revelatory, critical, extreme or unique unit of analysis. Just as well, a large number of homogenous cases provide strong support for conducting a cross-case analysis.

Germany comprises of 16 federal states and within these states there are altogether more than 11.000 municipalities. In order to reduce biases and analyze E-Procurement adoption from different perspectives, municipalities are selected as follows: From each German state - except for the city states Berlin, Bremen and Hamburg - the eighth largest municipality 
is selected. The eighth largest municipality of each state is selected as this ensures to some extent representativeness, with respect to municipality size and state affiliation. Due to the fact that municipal and state levels are intertwined, city states are judged as being incomparable with respect to responsibilities, and are excluded from the investigation. As a result, four large (more than 100.000 inhabitants), four medium- (between 100.000 and 40.000 inhabitants) and five small-sized (less than 40.000 inhabitants) municipalities are selected. By analyzing similarities across municipalities, thirteen cases are assumed to provide a rich basis testing hypotheses and identifying additional determinants of E-Procurement adoption at the municipal level.

\subsection{Data collection}

The multiple-case study took place within four weeks between February 17th 2010 and March 15th 2010. In six cases interview partners were either repeatedly unavailable or refused to participate in studies as a matter of principle. In that case, the next larger municipality within the state was selected. In four states, the seventh largest municipality was accessed. Only in one state, two municipalities declined to participate and the sixth largest municipality was selected.

Each case was investigated based on a semistructured telephone interview with an official. The interview partner was required to be either responsible for a significant area of public procurement within the municipality or to have insights in all procurement relevant decisions. As a result, officials with different backgrounds and competences were interviewed. Two interview partners were in charge of an E-Procurement project; three respondents were head of the central procurement department; three interviewees were head of the public construction department; and five interview partners were head or a responsible person of the central services department.

A case study protocol was used to purposefully guide the researcher during data collection entailing field procedures and case study questions. The field procedures gave attention to the situations and problems with which the investigator was confronted when he was approaching the unit of analysis and while data collection was carried out [25].

According to Benbasat et al. [1], confidentially and benefits to the organization are two important issues that need to be addressed in order to gain cooperation. As respondents were interviewed by telephone, this task was particularly difficult.

The benefit to the municipality was assured by offering respondents access to the final research results. Confidentiality was guaranteed by ensuring that participants' identity is kept secret and by allowing respondents to revise the draft interview transcript. Before the interview started, the respondents were asked for permission that the interview will be recorded. Except for one respondent who preferred to answer the questions in writing form, interview partners agreed that the interview is tape-recorded.

An interview guide governed the goals, tactics and techniques that are required to focus questions while leaving space for new ideas and opinions beyond the theoretical boundaries of the investigation [15]. The interviews were held on telephone for an average of 25 minutes. The interview guide kept interactions focused while allowing individual experiences to emerge and thus best uses the limited time available in the interview situation [29].

The case study questions entailed queries about the respondent's responsibility within the municipality, the degree of E-Procurement adoption and contextual factors. Moreover, open questions allowed the respondent to argue about additional factors influencing E-Procurement adoption.

The overall quality of the case study protocol was improved by conducting four pilot cases. The pilot cases were randomly selected out of the tenth largest municipalities of the 13 states. The results led to some minor modification of the case study protocol with respect to the order of questions. Moreover, the field procedures were optimized in order to be even more persuasive to potential interview partners.

\subsection{Data analysis}

The goal of the data analysis was to present the contextual and data richness of the study, establish a clear chain of evidence and clearly state and define the reasoning [1].

The interview transcripts were analyzed using the computer-assisted data analysis software Atlas.ti ${ }^{4}$. A coding scheme was developed to study common themes across interview partners' statements following the recommendations of Boyatzis [3].

For each proposed influence factor a code was created, which was used for identifying its occurrence in the interview transcript. A quote was coded each time the respondent argued that he or she perceives that a factor is influential for the adoption of E-Procurement.

Apart from developing codes from theory, a datadriven approach was taken to identify additional influence factors. In doing so, Employee Acceptance

\footnotetext{
${ }^{4}$ ATLAS.ti Scientific Software Development, Version 6.1, http://www.atlasti.com (accessed $27^{\text {th }}$ Mai 2010)
} 
Table 1. Occurrences of coded determinants

\begin{tabular}{|c|c|c|c|c|c|c|c|c|c|c|}
\hline Determinant & PRs* & PA* & PBs* & PI* & EA*** & FRs** & PC* & CE* $_{*}^{*}$ & LF* & IS* \\
\hline $\begin{array}{c}\text { Number of Interview Partners } \\
\text { who mention Determinant }\end{array}$ & 9 & 8 & 7 & 7 & 6 & 6 & 6 & 5 & 1 & 0 \\
\hline $\begin{array}{c}\text { Relative Number of Interview } \\
\text { Partners who mention Determinant }\end{array}$ & $69 \%$ & $62 \%$ & $54 \%$ & $54 \%$ & $46 \%$ & $46 \%$ & $46 \%$ & $38 \%$ & $8 \%$ & $0 \%$ \\
\hline
\end{tabular}

(*) Determinant of the conceptual model

could be determined as another determinant that influences E-Procurement adoption. Employee Acceptance refers to the degree to which employees are capable and willing to use E-Procurement tools.

In the final step, the developed codes were applied on all thirteen interview transcripts. The results are presented in the following.

\subsection{Results}

The final coding matrix (see Table 1) lists the number of interview partners who mention a determinant as being influential in decreasing order. For each determinant the most representative citations from the interviews is provided in this section.

Perceived Risks (PRs) is the strongest determinant for the adoption of E-Procurement and is supported by $69 \%$ of the participants. The main risks that impede a stronger diffusion of E-Procurement at the municipal level are financial and legal risks.

Security issues are not insignificant. Tendering procedures have to be set up in a way that ensures confidentiality and authenticity. A procedure, which involves an electronic signature may have a high security standard but this standard implies on closer examination additional costs. As contracting authorities are incumbent on securing mandatory standards, they are also exposed to additional liability risks (Municipality 11:5).

The second strongest determinant is Provider Acceptance (PA). 62 percent of interview partner mention this determinant as being influential.

The acceptance among small construction firms and manufacturers respectively would be low, since the vast majority of firms are incapable [to use E-Procurement]. This is totally logic. If we award contracts than window makers, cabinet makers and painters apply. They are unable to submit a bid electronically. They sometime still have old personal computers from the nineties for accounting purposes (Municipality 10:5).

Perceived Benefits (PBs) and Peer Influence (PI) are the third strongest predictors of adoption. They are deemed as influential by 54 percent of interviewees.
$(* *)$ Additional Determinant identified in the study

The adoption of electronic tendering certainly improves the speediness of procedures. To a certain extent, it will also lead to cost savings due to less paper consumption (Municipality 7:3).

You could increase acceptance when you bring persons together who are open to the idea. The interest groups should manage that smaller groups of municipalities exchange experiences regionally. [...] You can convince people when you demonstrate that E-Procurement works (Municipality 5:3).

Apart from IT Sophistication, organizational factors only moderately influence the adoption of E-Procurement. Employee Acceptance (EA), Financial Resources (FRs), Political Commitment (PC) and Centralization (CE) are the fourth and fifth strongest determinants of E-Procurement adoption. At least 5 of the 13 interview partners mention these determinants as being influential.

I have to admit that innovations are hard to introduce in the public administration in particular if public employees do not perceive any advantage (Municipality 12:2).

The budgetary position is absolutely bad. We get a biennial budget for 2010 and 2011. The budget proposal was rejected by the district committee. Thus, we do not have any budget and have to save about 240 million Euro in the planning period 2010-2014. You can imagine that no financial resources are available for additional actions (Municipality 4:1).

We are willing to be active in this area but it is hard to convince [...] politicians of the necessity. When you look at the potholes on the streets, nobody from the city council asks for electronic tendering. Potholes clearly have priority. There is no benefit for the city council to introduce electronic tendering (Municipality 13:2).

Our problem is that we do not have a central procurement unit, which addresses the topic. [...] If you have a central procurement unit in place, knowledge could be concentrated and the problem sorted out (Municipality 13:3). 
The weakest determinant of adoption is the Legal Framework (LF). Only one interview partner states that the LF impedes further adoption of E-Procurement.

The tools are not the problem. The idea had been mooted once but was then dismissed when we got the economic stimulus package. We have realized that we barely publish anything anymore. By the end of 2011, we are back to where we have been two years ago. And then we will see how we will proceed (Municipality 2:2).

Finally, IT Sophistication (IS) is not supported as a determinant of adoption by any interviewee.

\subsection{Discussion}

None of the proposed determinants is supported by more than 70 percent of the cases. The dissent among interview partners might be explained by their different backgrounds and responsibilities in public procurement. While similarities are harder to identify across more heterogeneous sources, the incorporation of feedback from different angles provides triangulation and improves the credibility of results.

The perceptions of risks and benefits to adopt E-Procurement are the strongest and third strongest determinants respectively. Electronic procedures have to meet the same legal requirements with respect to secrecy of bids and traceability as paper-based procedures. While the direct benefits of E-Procurement adoption are predominantly shared among municipalities, E-Procurement is unlikely to be widely adopted in the German public sector as long as existing solutions are perceived as heterogeneous, immature and costly.

Apart from the technological perspective, municipalities are mainly concerned about their local business community. In particular small handicraft businesses in the area of construction lack competences and resources to participate in electronic procedures. From the perspective of providers, the access to a tendering platform involves a considerable human asset specific investment as providers have to engage resources to become familiar with the functionalities and business opportunities of the electronic platforms [43]. The multitude of heterogeneous solutions in the public sector on the one hand and initial asset specific investment costs for providers on the other hand are supposed to further hinder the diffusion of E-Procurement at the municipal level.

Peer Influence is the third strongest determinant of E-Procurement adoption. The qualitative analysis reveals that municipalities want larger peer organizations like the state government or neighboring cities to pioneer the field as they have more resources to pursue E-Procurement adoption. As long as larger peer organizations have not adopted E-Procurement, municipalities will apply a wait-and-see strategy until a dominant design of E-Procurement emerges. In contrast, when the majority of peers already use E-Procurement, non-adopting peers may feel encouraged to adopt as well based on the experiences provided.

The strongest determinants of E-Procurement adoption are environmental and technical factors. The overall weak consensus across municipalities about the role of organizational factors might be partly explained by a known bias of qualitative interviews as the only evidentiary source. Respondents were unlikely to assess their own organizational situation as the key barrier of adoption.

Webb et al. [42] argue that qualitative interviews "[...] intrude as a foreign element into the social setting they would describe, they create as well as measure attitudes, they elicit atypical roles and responses, they are limited to those who are accessible and will cooperate, and the responses obtained are produced in part by dimensions of individual differences irrelevant to the topic at hand [...]." This became especially evident when interview partners were asked about the competences of their IT department. All interview partners tended to answer this question diplomatic and stated that the existing IT infrastructure and IT competences do not impede the adoption of E-Procurement. To improve the overall validity of the model, future research should investigate determinants in more detail by applying triangulation using additional evidentiary sources and data collection methods.

The existing legal framework was not perceived as a barrier of E-Procurement adoption at the municipal level. As the legal framework already entails regulations about using electronic means, this may not be so surprising at first sight. Future work should rather concentrate on the question if and how E-Procurement adoption can be reasonably increased by enforcing certain capabilities to be available.

\section{Conclusion}

This study focused on determinants of E-Procurement adoption at the municipal level. Based on the existing literature, a conceptual model was developed, which was further elaborated by collecting and analyzing data from a multiple-case study of 13 German municipalities.

The four strongest determinants identified in our study were Perceived Risks, Local Provider Acceptance, Perceived Benefits and Peer Influence. Moreover, moderate support was found for three 
proposed organizational determinants (Financial Resources, Political Commitment and Centralization) and an additional one (Employee Acceptance) who was identified as part of the exploratory analysis.

The results are a first step to develop a full understanding of E-Procurement adoption behaviors at the municipal level. Rigorous strategies were used throughout the whole research process. However, a limited number of 13 cases make it particularly hard to find compelling support for the proposed determinants. Thus, more research is needed relying on multiple data collection methods as well as more comprehensive evidentiary sources. Finally, the conceptual model should be tested using quantitative methods.

\section{References}

[1] I. Benbasat, D.K. Goldstein, and M. Mead, "The Case Research Strategy in Studies of Information Systems," MIS Quarterly, vol. 11, Sep. 1987, pp. 369386.

[2] L. Bouchard, "Decision criteria in the adoption of EDI," Proceedings of the 14th International Conference on Information Systems, Orlando, Florida: 1993, pp. 365-376.

[3] R.E. Boyatzis, Transforming Qualitative Information: Thematic Analysis and Code Development, Sage Publications, Inc, 1998.

[4] L. Carter and F. Bélanger, "The utilization of egovernment services: citizen trust, innovation and acceptance factors," Information Systems Journal, vol. 15,2005 , pp. 5-25.

[5] S.L. Caudle, W.L. Gorr, and K.E. Newcomer, "Key Information Systems Management Issues for the Public Sector," MIS Quarterly, vol. 15, Jun. 1991, pp. 171188.

[6] P.Y.K. Chau and K.Y. Tam, "Organizational adoption of open systems: a 'technology-push, needpull' perspective," Information \& Management, vol. 37, Aug. 2000, pp. 229-239.

[7] P.Y.K. Chau and K.Y. Tam, "Factors Affecting the Adoption of Open Systems: An Exploratory Study," MIS Quarterly, vol. 21, Mar. 1997, pp. 1-24.

[8] K. Christmann, D. Huland, and B. Meißner, Einkaufen für Kommunen: Modern, wirtschaftlich und rechtssicher, Jehle, 2004.

[9] P. Chwelos, I. Benbasat, and A.S. Dexter,
"Research Report: Empirical Test of an EDI Adoption Model," Information Systems Research, vol. 12, Sep. 2001, pp. 304-321.

[10] D. Coursey and D.F. Norris, "Models of EGovernment: Are They Correct? An Empirical Assessment," Public Administration Review, vol. 68, Jun. 2008, pp. 523-536.

[11] F.D. Davis, "Perceived Usefulness, Perceived Ease of Use, and User Acceptance of Information Technology," MIS Quarterly, vol. 13, Sep. 1989, pp. 319-340.

[12] European Commission, The access of SMEs to public procurement contracts, 2004.

[13] M. Fishbein and I. Ajzen, Belief, attitude, intention and behavior: An introduction to theory and research, Free Press, 1975.

[14] J. Gerring, Case Study Research: Principles and Practices, Cambridge University Press, 2006.

[15] R.L. Gorden, Interviewing: Strategy, Techniques, and Tactics, Chicago, Ill.: Dorsey Press, 1987.

[16] E.E. Grandon and J.M. Pearson, "Electronic commerce adoption: an empirical study of small and medium US businesses," Information \& Management, vol. 42, Dezember. 2004, pp. 197-216.

[17] V. Gurbaxani and S. Whang, "The impact of information systems on organizations and markets," Communication of the ACM, vol. 34, 1991, pp. 59-73.

[18] P. Hart and C. Saunders, "Power and Trust: Critical Factors in the Adoption and Use of Electronic Data Interchange," Organization Science, vol. 8, Feb. 1997, pp. 23-42.

[19] H.Z. Henriksen and V. Mahnke, "E-Procurement Adoption in the Danish Public Sector," Scandinavian Journal of Information Systems, vol. 17, 2005, pp. 526.

[20] F. Hogrebe, N. Blinn, and M. Nüttgens, "Survey of E-Government Portals in European Capitals and Large Cities: A Benchmarking Study of G2BServices," Proceedings of the 8th International Conference on Electronic Government, Linz, Austria: Springer-Verlag, 2009, pp. 188-197.

[21] C. Iacovou, I. Benbasat, and A.S. Dexter, "Electronic Data Interchange and Small Organizations: 
Adoption and Impact of Technology," MIS Quarterly, vol. 19, Dec. 1995, pp. 465-485.

[22] M.M. Kamal, "IT innovation adoption in the government sector: identifying the critical success factors," Journal of Enterprise Information Management, vol. 19, 2006, pp. 192 - 222.

[23] E. Kosilek, Elektronische Beschaffung in Kommunen, Eul Publishing House, 2004.

[24] J. von Lucke, "E-Government - Barrieren und Hindernisse," Electronic Government in Deutschland, J. Reinermann and J. von Lucke, Eds., Speyer: 2002, pp. 65-93.

[25] R.K. Merton, M. Fiske, and P.L. Kendall, Focused Interview: A Manual of Problems and Procedures, Free Press, 1990.

[26] Ministers of European Union, Ministerial Declaration approved unanimously on 24 November 2005, Manchester, United Kingdom, 2005.

[27] M.J. Moon, "E-Procurement Management in State Governments: Diffusion of E-Procurement Practices and its Determinants," Journal of Public Procurement, vol. 5, 2005, pp. 54-72.

[28] A. Nekolar, E-Procurement: Euphorie und Realität, Springer, 2002.

[29] M.Q. Patton, Qualitative Research \& Evaluation Methods, Sage Pubn Inc, 2002.

[30] T. Puschmann and R. Alt, "Successful use of eprocurement in supply chains," Supply Chain Management: an international journal, vol. 10, 2005, pp. 122-33.

[31] H.G. Rainey, R.W. Backoff, and C.H. Levine, "Comparing Public and Private Organizations," Public Administration Review, vol. 36, Apr. 1976, pp. 233 244.

[32] S. Ramanathan, "Diffusion of eProcurement in the Public Sector - Revisiting Centralization versus Decentralization Debates as a Twist in the Tale," ECIS 2004 Proceedings, Paper 114: 2004.

[33] C. Reddick, "The growth of e-procurement in American state governments: a model and empirical evidence," Journal of Public Procurement, vol. 4,
2004, pp. 151-176.

[34] E.M. Rogers, Diffusion of Innovations, 5th Edition, Free Press, 2003.

[35] A. Ruff, Public Electronic Procurement: Elektronische Vergabe und Beschaffung von Lieferungen und Leistungen der KommunalVerwaltung über Internet, GUC Gesellschaft f. Unternehmensrechnung u. Controlling, 2009.

[36] P. Stoll, Der Einsatz von E-Procurement in mittelgroßen Unternehmen: Konzeptionelle Überlegungen und explorative Untersuchung, Gabler, 2008.

[37] E.B. Swanson, "Information Systems Innovation among Organizations," Management Science, vol. 40, Sep. 1994, pp. 1069-1092.

[38] R. Titah and H. Barki, "E-government adoption and acceptance: a literature review," International Journal of Electronic Government Research, vol. 2, 2006, pp. 23-57.

[39] L.G. Tornatzky and M. Fleischer, Processes of Technological Innovation, Lexington Books, 1990.

[40] E. Turban, J.K. Lee, D. KIng, J. McKay, and P. Marshall, Electronic Commerce 2008, Prentice Hall, 2007.

[41] K. Vaidya, A.S.M. Sajeev, and G. Callender, "Critical factors that influence e-procurement implementation success in the public sector," Journal of public procurement, vol. 6, 2006, p. 70.

[42] E.J. Webb, D.T. Campbel, R.D. Schwartz, and L. Sechrest, Unobtrusive measures, Thousand Oaks [u.a.]: SAGE, 2000.

[43] O.E. Williamson, Economic organization: firms, markets and policy control, Brighton, Sussex: Wheatsheaf Books, 1986.

[44] R.K. Yin, Case Study Research: Design and Methods, Sage Publications, Inc, 2008.

[45] K. Zhu, K.L. Kraemer, V. Gurbaxani, and S. Xin $\mathrm{Xu}$, "Migration to open-standard interorganizational systems: Network effects, switching costs and path dependency," MIS Quarterly, vol. 30, Aug. 2006, pp. 515-539. 